\title{
Relative Importance of Deterministic and Stochastic Processes on Soil Microbial Community Assembly in Temperate Grasslands
}

\author{
Nana Liu ${ }^{1,2}{ }^{\oplus}$, Huifeng $\mathrm{Hu}^{2}$, Wenhong $\mathrm{Ma}^{3}$, Ye Deng ${ }^{4}{ }^{\oplus}$, Qinggang Wang ${ }^{5}{ }^{\circledR}$, Ao Luo ${ }^{1}$, Jiahui Meng ${ }^{1}$, \\ Xiaojuan Feng $2, * \mathbb{C}$ and Zhiheng Wang $1, * \mathbb{B}$
}

1 Institute of Ecology and Key Laboratory for Earth Surface Processes of the Ministry of Education, College of Urban and Environmental Sciences, Peking University, Beijing 100871, China; nnliu@pku.edu.cn (N.L.); luoao@pku.edu.cn (A.L.); mengiahui@pku.edu.cn (J.M.)

2 State Key Laboratory of Vegetation and Environmental Change, Institute of Botany, Chinese Academy of Sciences, Beijing 100093, China; huifhu@ibcas.ac.cn

3 College of Ecology and Environment, Inner Mongolia University, Hohhot 010021, China; whmapku@126.com

4 CAS Key Laboratory of Environmental Biotechnology, Research Center for Eco-Environmental Sciences, Chinese Academy of Sciences, Beijing 100085, China; yedeng@rcees.ac.cn

5 Key Laboratory of Biodiversity and Organic Farming, Department of Ecology and Ecological Engineering, College of Resources and Environmental Sciences, Agricultural University, Beijing 100193, China; wangqg@cau.edu.cn

* Correspondence: xfeng@ibcas.ac.cn (X.F.); zhiheng.wang@pku.edu.cn (Z.W.)

check for

updates

Citation: Liu, N.; Hu, H.; Ma, W.; Deng, Y.; Wang, Q.; Luo, A.; Meng, J.; Feng, X.; Wang, Z. Relative

Importance of Deterministic and

Stochastic Processes on Soil Microbial Community Assembly in Temperate Grasslands. Microorganisms 2021, 9 , 1929. https://doi.org/10.3390/ microorganisms 9091929

Academic Editor: Lorenzo Brusetti

Received: 21 August 2021

Accepted: 7 September 2021

Published: 10 September 2021

Publisher's Note: MDPI stays neutral with regard to jurisdictional claims in published maps and institutional affiliations.

Copyright: (c) 2021 by the authors. Licensee MDPI, Basel, Switzerland. This article is an open access article distributed under the terms and conditions of the Creative Commons Attribution (CC BY) license (https:/ / creativecommons.org/licenses/by/ $4.0 /)$.
Abstract: Changes in species composition across communities, i.e., $\beta$-diversity, is a central focus of ecology. Compared to macroorganisms, the $\beta$-diversity of soil microbes and its drivers are less studied. Whether the determinants of soil microbial $\beta$-diversity are consistent between soil depths and between abundant and rare microorganisms remains controversial. Here, using the 16S-rRNA of soil bacteria and archaea sampled at different soil depths $(0-10$ and $30-50 \mathrm{~cm})$ from 32 sites along an aridity gradient of $1500 \mathrm{~km}$ in the temperate grasslands in northern China, we compared the effects of deterministic and stochastic processes on the taxonomic and phylogenetic $\beta$-diversity of soil microbes. Using variation partitioning and null models, we found that the taxonomic $\beta$-diversity of the overall bacterial communities was more strongly determined by deterministic processes in both soil layers (the explanatory power of environmental distance in topsoil: $25.4 \%$; subsoil: $47.4 \%$ ), while their phylogenetic counterpart was more strongly determined by stochastic processes (the explanatory power of spatial distance in topsoil: 42.1 ; subsoil $24.7 \%$ ). However, in terms of abundance, both the taxonomic and phylogenetic $\beta$-diversity of the abundant bacteria in both soil layers was more strongly determined by deterministic processes, while those of rare bacteria were more strongly determined by stochastic processes. In comparison with bacteria, both the taxonomic and phylogenetic $\beta$-diversity of the overall abundant and rare archaea were strongly determined by deterministic processes. Among the variables representing deterministic processes, contemporary and historical climate and aboveground vegetation dominated the microbial $\beta$-diversity of the overall and abundant microbes of both domains in topsoils, but soil geochemistry dominated in subsoils. This study presents a comprehensive understanding on the $\beta$-diversity of soil microbial communities in the temperate grasslands in northern China. Our findings highlight the importance of soil depth, phylogenetic turnover, and species abundance in the assembly processes of soil microbial communities.

Keywords: community composition; environmental selection; dispersal limitation; subsoil microbial diversity; rare microbes; bacteria; archaea

\section{Introduction}

Changes in community species composition across space (i.e., $\beta$-diversity) is a central focus of ecology and is vital for understanding community assembly processes [1,2]. Al- 
though this issue has been widely explored in terrestrial plant and animal communities [3,4], it has been much less investigated in microbial communities $[1,5,6]$. Most studies on microbial $\beta$-diversity have been focused on topsoil $(0-10 \mathrm{~cm})[7,8]$, while few studies have examined microbial $\beta$-diversity in subsoils (below $30 \mathrm{~cm}$ ) [9]. Compared to topsoils, subsoils generally have lower substrate availability, longer substrate turnover time in organic matter, and better insulation from the atmosphere [10], all of which may lead to the fact that subsoils are more sensitive and vulnerable to climate change [11,12]. Therefore, exploring the biogeographic patterns of $\beta$-diversity and the driving mechanisms in subsoil microbial communities will improve our understanding not only of the assembly processes of soil microbial communities but also of the responses of soil microbial communities to environmental changes.

Soil microbial $\beta$-diversity is frequently determined by two dominant processes: deterministic and stochastic processes $[1,2]$. Deterministic processes suggest that microbial $\beta$-diversity is determined by abiotic and biotic factors that represent the effects of environmental selection on microbial community composition [1]. In contrast, stochastic processes suggest that microbial $\beta$-diversity is determined by dispersal limitation, ecological drifts, genetic mutation, and historical contingencies [1,2]. Evaluating the relative contributions of deterministic and stochastic processes is critical for understanding the mechanisms of microbial community assembly but remains a challenge in current studies. Several statistical approaches have been developed to examine the relative importance of deterministic and stochastic processes, among which the distance-decay relationship (DDR) have been widely used [13]. This method evaluates the changes in the community composition along spatial and environmental gradients [14]. A steeper DDR slope implies a faster turnover in the species composition across a landscape [15]. Null models have also been used to infer ecological stochasticity by comparing the observed patterns with the expected random patterns produced by null models $[6,16]$.

Studies have found that the relative importance of the deterministic and stochastic processes on soil microbial communities varies across environmental gradients (e g., $\mathrm{pH}$, nutrients, and climate) $[17,18]$, succession stages [19], and different functional assemblages $[20,21]$. However, the relative importance of these driving factors across different soil depths is unknown. Studies have shown that soil microbial communities are controlled by deterministic processes more than by stochastic processes in topsoils $(0-10 \mathrm{~cm})$ and that the deterministic factors are mainly climate-related factors [2]. In contrast, given the relatively well-insulated and oligotrophic environments in subsoils, the microbial communities in subsoils may also be strongly driven by deterministic processes but through different environmental factors, such as soil geochemical factors (i.e., soil pH) $[17,22]$. However, whether the drivers of microbial $\beta$-diversity are consistent across different soil depths remains to be tested.

Previous studies on terrestrial plants and animals have demonstrated that $\beta$-diversity and its drivers differed between abundant and rare microorganisms due to their different dispersal abilities [3] and environmental preferences [23,24]. Specifically, studies have suggested that the $\beta$-diversity of abundant plants and animals tends to be determined by deterministic processes $[3,23,24]$, while that of rare microorganisms tends to be determined by stochastic processes [3]. Similar to plants and animals, most microbial communities normally contain large numbers of rare microbes and a few highly abundant microorganisms [25]. Current studies show inconsistent evidence for the relative importance of deterministic and stochastic processes on the $\beta$-diversity of rare and abundant soil microbes [25-27]. The generality of the previous findings based on plants and animals for soil microbial communities remains poorly known.

Here, we evaluated the microbial $\beta$-diversity and its drivers in top- $(0-10 \mathrm{~cm})$ versus subsoils $(30-50 \mathrm{~cm}$ ) along an aridity gradient of $1500 \mathrm{~km}$ in temperate grasslands in Inner Mongolia, China. The transect covers arid to mesic ecosystems and spans a wide range of climate and soil physicochemical conditions with varying plant species richness. In a previous study, we demonstrated the geographical patterns in soil bacterial and archaeal 
$\alpha$-diversity along this transect and their drivers using $16 \mathrm{~S}$ rRNA sequencing [28]. In the current study, we compared the relative effects of deterministic and stochastic processes on the $\beta$-diversity of soil bacterial and archaeal communities in both topsoils and subsoils. With these analyses, we aim to test the following hypotheses: (1) Soil microbial $\beta$-diversity in both soil layers is determined by deterministic processes, but the role of deterministic processes is stronger in subsoils than in topsoils; (2) the $\beta$-diversity and its drivers differ between abundant and rare soil microbes due to their different dispersal abilities and environmental preferences. Deterministic processes dominate the $\beta$-diversity of abundant microbes, while stochastic processes dominate that of rare microbes; (3) the environmental drivers representing the effects of deterministic processes on microbial $\beta$-diversity are distinct across soil depths and among taxa with different abundances.

\section{Materials and Methods}

\subsection{Soil Samples and Data Collection}

We collected 32 soil samples along an $\sim 1500-\mathrm{km}$ aridity transect from arid to mesic grasslands in Inner Mongolia (Longitude: from 107.929 to $119.970^{\circ} \mathrm{E}$; latitude, from 39.154 to $49.618^{\circ} \mathrm{N}$; Figure S1), China, in August 2015 [29]. The transect is in a temperate climatic zone with wind from Siberia all year round and varied climatic, edaphic, and vegetation conditions. It covers several vegetation types, including desert steppe (DS), typical steppe (TS), and meadow steppe (MS), from the southwest towards the northeast [30]. The desert steppe is arid, has low plant species richness, and is dominated by perennial drought-adaptive species including Stipa klemenzii and Stipa breviflora, etc. [30]. The typical steppe has the highest coverage in Inner Mongolian, with intermediate levels of net primary productivity (NPP) and plant species richness. The dominant species in the typical steppe are S. grandis, S. krylovii, and Artemisia frigida, etc. The meadow steppe has the highest NPP and plant species richness, and the dominant species are Stipa baicalensis and Leymus chinensis, etc. [30]. The mean annual precipitation (MAP) increases from 165.0 to $411.5 \mathrm{~mm}$, and the mean annual temperature (MAT) decreases from 6.4 to $-2.3^{\circ} \mathrm{C}$ from the southwest towards the northeast. Soil types along this transect include Calcisols, Kastanozems, and Calcic Chernozems [30]. The soil $\mathrm{pH}$ and soil organic carbon content in the topsoils along this transect range from 7.7 to 9.9 and from 0.39 to $4.69 \%$, respectively (see Supplementary Data).

Soil samples were collected from two relatively contrasting soil depths: $0-10 \mathrm{~cm}$ (topsoil) and 30-50 cm (subsoil) [28]. A total of seventeen environmental variables related to climate, plants, and soil properties were compiled or measured (see Supplementary Data). The climate-related variables included MAP, MAT, aridity index, soil water content (SWC, $\mathrm{mm} \mathrm{month}^{-1}$ ), and historical temperature anomaly. The historical temperature anomaly was calculated as the contemporary MAT minus that during the Last Glacial Maximum (LGM, i.e., the most recent glaciation, ca. 21,000 to 18,000 years before present day) [31]. Contemporary MAP and MAT data from 1950 to 2000 and data for the MAT during the LGM were obtained from the WorldClim website (http://worldclim.org/version2 accessed on 10 May 2017) [32], and the aridity index and SWC data were obtained from https:/ / cgiarcsi.community / accessed on 10 May 2017.

The plant-related variables included aboveground vegetation biomass, plant species richness, and NPP. The vegetation biomass and plant species richness were measured during sampling, and the NPP was obtained from the Numerical Terradynamic Simulation Group (NTSG) (http:/ /www.ntsg.umt.edu/project/modis/mod17.php; Missoula, MT, USA accessed on 10 May 2017). The soil-related variables including soil total nitrogen, soil total carbon, soil organic carbon, soil total phosphorus, soil $\mathrm{pH}$, soil extractable $\mathrm{Fe}$, soil extractable $\mathrm{Al}$, soil clay content, soil silt content, and soil sand content were measured and used (see Supplementary Data). More details related to soil sampling and soil parameter measurement were described in [28]. 


\subsection{DNA Extraction, High-Throughput Amplicon Sequencing and Sequence Processing}

Total soil DNA was extracted using the MoBio PowerSoil DNA isolation kit (MoBio Laboratories, Carlsbad, CA, USA). The V4 region of the 16S rRNA gene for bacteria was amplified using the barcoding primer pair 515F/806R (515F, 5'-GTGCCAGCMGCCGCGGTAA-3'; 806R, $5^{\prime}$-GGACTACHVGGGTWTCTAAT-3') [33]. A region of the 16S rRNA gene for archaea was amplified using the primer pair 1106F/1378R (1106F, $5^{\prime}$-TTWAGTCAGGCAACGAGC$3^{\prime} ; 1378 R$, 5'-TGTGCAAGGAGCAGGGAC-3') [34]. The DNA samples were sent to Novogene (Beijing, China) for sequencing using an Illumina HiSeq2500 platform.

Sequences generated from amplicon-based sequencing were processed using UPARSE (Tiburon, CA, USA) [35] on the Galaxy pipeline in the Metagenomics for Environmental Microbiology (http:/ / mem.rcees.ac.cn:8080) [36] in 15 June 2017. Finally, a total of 3,531,946 and 4,086,723 high-quality sequences were obtained for the soil bacteria and archaea and were grouped into 23,458 and 3152 OTUs, respectively, at a $97 \%$ sequence similarity cut-off. The sequence data in each community were resampled to 32,885 and 50,347 sequences per sample (the smallest number of sequences per sample across the samples) for bacteria and archaea, respectively. The 16S rRNA sequence data were analyzed in a previous study [28], and further analyses were conducted in this study.

We defined 'abundant' microbes as OTUs with an abundance $\geq 0.1 \%$ in all samples, and the 'rare' microbes were defined as OTUs with an abundance $\leq 0.01 \%$ in all samples. These thresholds were modified from Dai et al. [37].

\subsection{Statistical Analysis}

\subsubsection{Estimation of Soil Microbial $\beta$-Diversity}

The pairwise Bray-Curtis similarity (taxonomic $\beta$-diversity) and weighted UniFrac similarity (phylogenetic $\beta$-diversity) between each pair of communities were calculated using the 'vegan' and 'phyloseq' packages [38]. $\beta$-diversity patterns were visualized by nonmetric multidimensional scaling ordination (NMDS) with significant groupings at the $95 \%$ confidence interval. There were three different nonparametric multivariate statistical tests (Adonis, permutational multivariate analysis of variance; ANOSIM, analysis of similarity; MRPP, multiresponse permutation procedure) that were used to test the significance of $\beta$-diversity variation between the two communities. Multivariate homogeneity of group dispersions (variances) was conducted to test the multivariate dispersion between the topsoils and subsoils at $p<0.05$ [39]. NMDS, nonparametric multivariate statistical tests, and multivariate dispersion were performed using the 'vegan' package.

\subsubsection{The Relationship between Microbial $\beta$-Diversity and Distance}

Spatial distance was calculated from the geographic coordinates (latitude and longitude) of the sampled sites using the 'geosphere' package. The composite environmental distance between each pair of communities was calculated as the Euclidean distance generated from a normalized combination of six environmental groups, including (1) historical temperature anomaly; (2) contemporary climate; (3) aboveground vegetation; (4) soil fertility; (5) soil $\mathrm{pH}$; and (6) soil mineral content (Table S2). The relationships between the microbial $\beta$-diversity and both the spatial and environmental distances were analyzed using ordinary least-squares regressions to demonstrate the distance-decay curves. The slopes of these distance-decay curves were extracted to represent the species turnover rate. The significance of the distance-decay curves was tested using the Mantel test [40], and the significance of the difference in the slopes of the distance-decay curves between the two regression lines was assessed by analysis of variance (ANOVA) and pairwise comparisons of least squares means (LSMeans) using the 'lsmeans' package [41].

\subsubsection{Variation Partitioning and Null Model Analysis}

Variation partitioning was conducted to determine the relative contribution of spatial versus environmental distances to microbial $\beta$-diversity using the 'vegan' package. Using this method, the total variance in the microbial $\beta$-diversity was partitioned into 
four parts: the independent and shared effects of spatial and environmental distances and residuals [42]. Null model analyses (999 randomizations) were used to decipher community assembly mechanisms and to provide critical insights into the role of variable selection, homogenous selection, homogenous dispersal, dispersal limitation, and drift in shaping microbial $\beta$-diversity [6]. The evaluation of the five community assembly processes was based on the phylogenetic $\beta$-nearest taxon index $(\beta \mathrm{NTI})$ and Raup-Crick $\left(\mathrm{RC}_{\text {Bray }}\right) \beta$-diversity metrics [6]. The $\beta$ NTI was based on a null model test of the phylogenetic $\beta$-diversity index $\beta$ MNTD ( $\beta$ mean nearest-taxon distance), and $\mathrm{RC}_{\text {Bray }}$ (modified Raup-Crick index) was based on a null model test of the Bray-Curtis taxonomic $\beta$-diversity index. A significant $\beta N T I$ (i.e., $|\beta N T I|>2$ ) indicates the dominance of the selection effect on microbial community assembly. More specifically, $\beta \mathrm{NTI}>2$ indicates significantly more phylogenetic turnover than expected (i.e., variable selection), while $\beta$ NTI $<-2$ indicates significantly less phylogenetic turnover than expected (i.e., homogenous selection). $|\beta N T I|<2$ indicates the dominance of stochasticity, which, in combination with RCBray, further deciphers the effect of stochasticity. Specifically, $|\beta N T I|<2$ and $\mathrm{RC}_{\text {Bray }}<-0.95$ indicate homogenous dispersal. $|\beta \mathrm{NTI}|<2$ and $\mathrm{RC}_{\text {Bray }}>0.95$ indicate dispersal limitation. $|\beta \mathrm{NTI}|<2$ and $\left|\mathrm{RC}_{\text {Bray }}\right|<0.95$ indicate 'undominated processes', including weak selection, weak dispersal, and diversification and drift $[1,6]$.

\subsubsection{Random Forest Analysis}

Random forest analysis [43] was conducted to determine the importance of spatial distance and individual environmental factors in structuring microbial $\beta$-diversity. The importance of each factor was determined by evaluating the increase in the mean square error between observations and out-of-bag predictions when the factors were randomly permuted in over 500 trees [44]. The merit of random forest analysis is to alleviate multicollinearity problems in multivariate analysis by building bagged tree ensembles and by including a random subset of features for each tree (500 trees). The random forest analysis was conducted using the 'randomForest' package.

\subsubsection{Estimation of Habitat Niche Breadth}

The habitat niche breadth of a microbial community is an important trait underlying the relative importance of deterministic and stochastic processes [45]. We calculated the community habitat niche breadths (Levins' niche breadths) using the 'niche.width' function in the 'spaa' package in R [46]. The significance of the difference in the habitat niche breadths between the topsoils versus the subsoils and among the three communities was evaluated by paired t-tests and Tukey's multiple comparisons at $p<0.05$ using the 'HSD.test' function in the 'agricolae' package.

All of the analyses were conducted in R software (version 3.6.2; Vienna, Austria).

\subsection{Accession Numbers}

HiSeq2500 sequencing data have been deposited in the public National Center for Biotechnology Information (NCBI) database with the accession number PRJNA557316.

\section{Results}

\subsection{Microbial Communities in Top- and Subsoils}

All three nonparametric multivariate statistical tests (Adonis, ANOSIM, and MRPP) for the nonmetric multidimensional scaling ordination analysis indicated that the taxonomic and phylogenetic $\beta$-diversity for bacteria and archaea significantly differed between the top- and subsoils $(p<0.05)$ (Figure 1a-d and Table S1). Specifically, the taxonomic $\beta$-diversity for the archaea was significantly more dispersed in the subsoils than in the topsoils $(p<0.05$, Figure 1e,f). The topsoils generally contained more Acidobacteria, Alphaproteobacteria, Verrucomicrobia, Planctomycetes, Bacteroidetes, Betaprotobacteria, Firmicutes, and Crenarchaeota than subsoils based on their relative abundance, while the subsoils contained more Actinobacteria, Nitrospirae, Gemmatimonadetes, Euryarchaeota, and Parvarchaeota 
(Figure 1g,h). In addition, the bacterial and archaeal communities in both soil layers included a large number of rare microbial taxa with low abundances and few abundant taxa with high abundances (Figure 1i,j).
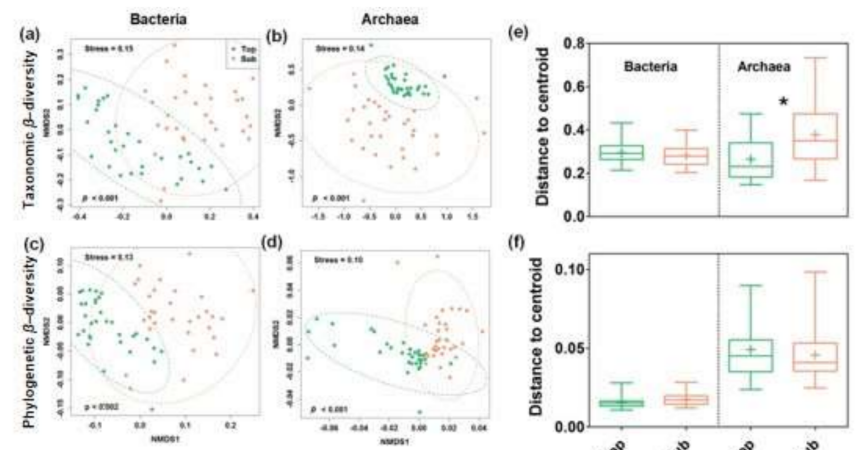

(f)
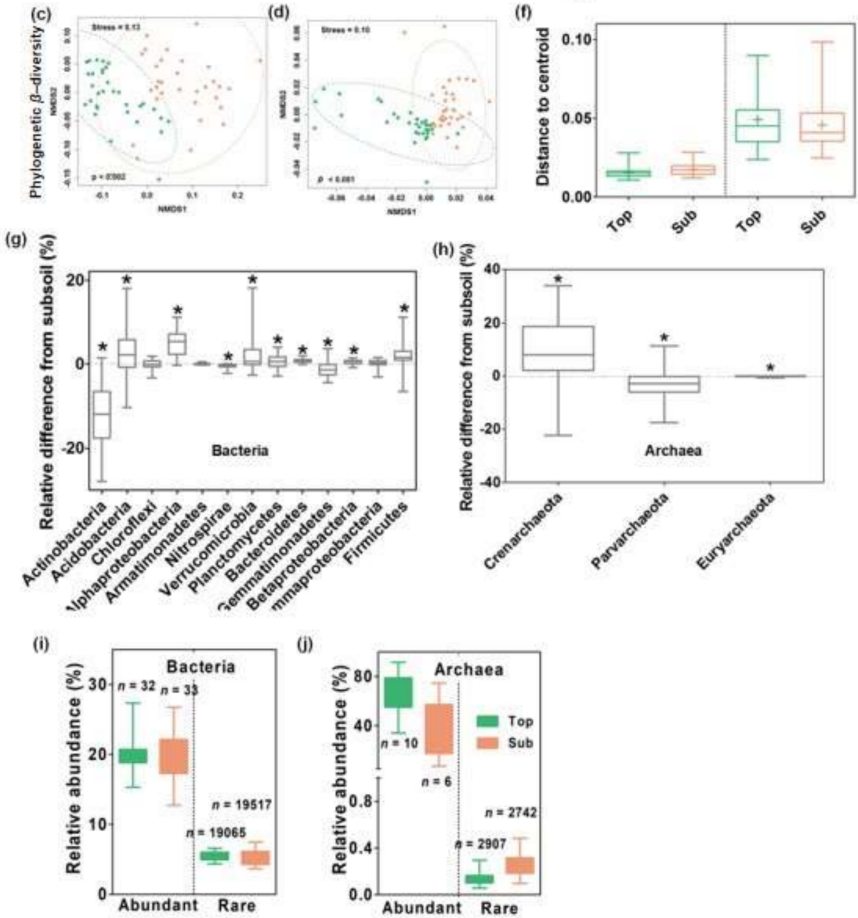

Figure 1. Soil bacterial and archaeal community composition across soil depths in temperate grasslands. Taxonomic and phylogenetic $\beta$-diversity was evaluated using Bray-Curtis and weighted UniFrac distances, respectively. (a-d) Nonmetric multidimensional scaling (NMDS) ordination showed differences in the taxonomic and phylogenetic $\beta$-diversity of the bacterial and archaeal communities between topsoils (green) and subsoils (salmon). Dashed lines represent significant groupings in both soil layers at the $95 \%$ confidence interval, and the difference between soil layers was statistically tested by all three nonparametric multivariate statistical tests (Adonis, ANOSIM and MRPP; Table S1). (e,f) Analysis of multivariate homogeneity of group dispersions (variances) was conducted to compare the taxonomic or phylogenetic $\beta$-dispersion between the topsoils and subsoils. $(\mathbf{g}, \mathbf{h})$ The relative difference in abundance between the topsoils and subsoils for different microbial groups was calculated as the relative abundance of groups in topsoils minus that in subsoils. The asterisk $\left(^{*}\right)$ represents significant difference of the relative abundance between top- and subsoils at $p<0.05$. (i,j) Panels indicate the relative abundance of abundant and rare microorganisms across soil depths, with $n$ indicating the OTU numbers.

\subsection{Distance-Decay Relationships in Top-and Subsoils}

As indicated by the distance-decay curves, the taxonomic and phylogenetic similarity between the microbial communities significantly decreased with both spatial and environmental distances in both the bacterial and archaeal communities $(p<0.05$; Figure 2a,b,d,e,g-k), indicating distance-decay patterns. The slopes of the distance-decay curves indicate the community turnover rate, and we found that the bacterial communities in the topsoils had faster turnover rates in the taxonomic and phylogenetic $\beta$-diversity than those in the subsoils (Figure $2 \mathrm{c}, \mathrm{f})$. In contrast, archaeal communities had inconsistent community turnover rates in the taxonomic and phylogenetic $\beta$-diversity in both the topsoils and subsoils (Figure 2i,l). The 
slopes of the distance-decay curves across spatial and environmental distances indicate the relative importance of spatial and environmental distances, and we found that the phylogenetic $\beta$-diversity for the bacterial communities in the topsoils was more strongly associated with spatial distance, while the taxonomic $\beta$-diversity in the subsoils was more strongly associated with environmental distance (Figure $2 \mathrm{c}, \mathrm{f}$ ). In comparison, the archaeal $\beta$-diversity in both soil layers was more strongly associated with environmental distance (Figure 2i,l).

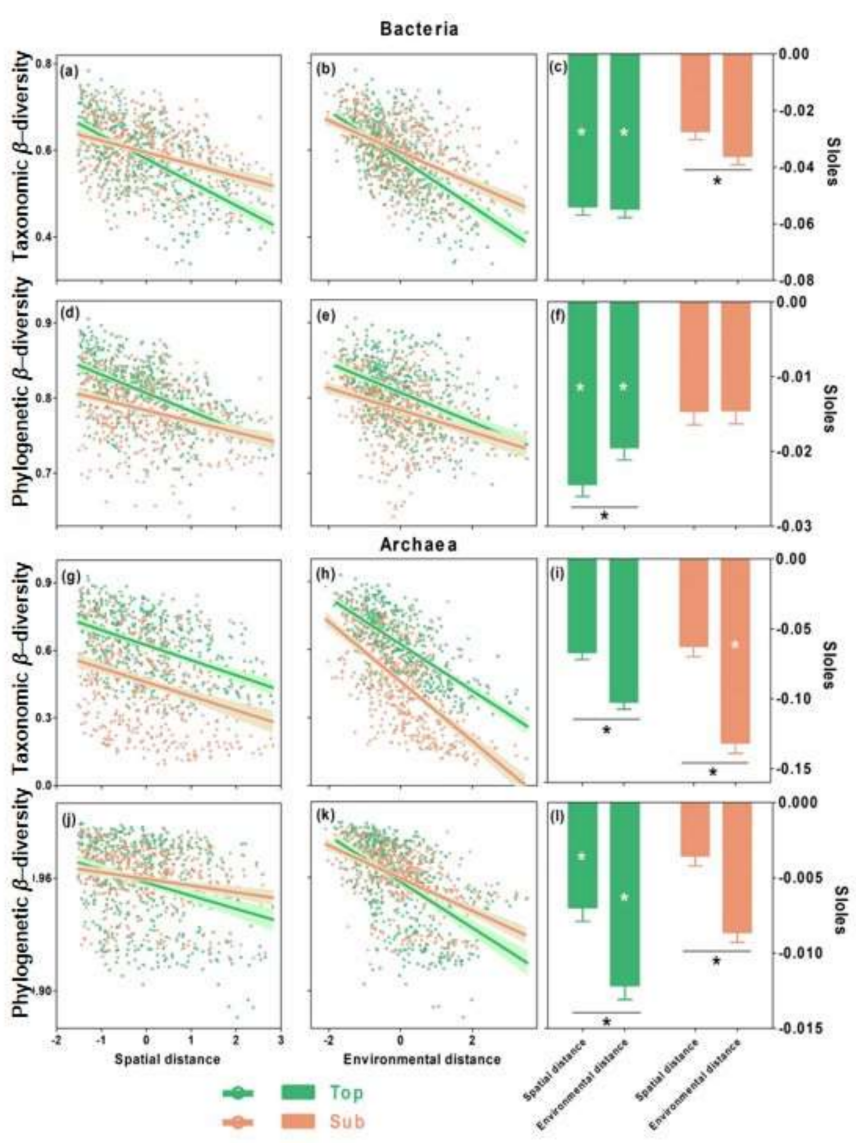

Figure 2. Changes in taxonomic and phylogenetic $\beta$-diversity of bacterial $(\mathbf{a}-\mathbf{f})$ and archaeal (g-l) communities as functions of spatial and environmental distances and their corresponding slopes in topsoils and subsoils. Taxonomic and phylogenetic $\beta$-diversity was evaluated using BrayCurtis and weighted UniFrac similarities, respectively. Green and salmon colours indicate topsoils and subsoils, respectively. Solid lines represent significant linear regressions $(p<0.05)$ for the relationships between the $\beta$-diversity and the distances evaluated by the Mantel test. The slopes between the $\beta$-diversity and the spatial/environmental distances were compared between the top-and subsoils ( ${ }^{*}$ on the bars) and between the spatial and environmental distances ( ${ }^{*}$ below the bars) at $p<0.05$. Environmental distance was generated by computing the Euclidean distance among six environmental variables, including historical temperature anomaly, contemporary climate, aboveground vegetation, soil fertility, soil $\mathrm{pH}$, and soil mineral content (Table S2). Spatial and environmental distances were standardized to be comparable.

We further found that the taxonomic and phylogenetic $\beta$-diversity of the abundant and rare microorganisms for the bacterial and archaeal communities showed significant $(p<0.05)$ distance-decay patterns with both spatial and environmental distances in both soil layers (Figure $3 \mathrm{a}-\mathrm{d}, \mathrm{f}-\mathrm{i}, \mathrm{k}-\mathrm{n}, \mathrm{p}-\mathrm{s}$ ), with the exception of the phylogenetic $\beta$-diversity of the rare bacterial and archaeal taxa in subsoils. Interestingly, the $\beta$-diversity of abundant bacterial taxa was more strongly associated with environmental distance, while rare bacterial taxa were more strongly associated with spatial distance, as illustrated by the comparison of the slopes along the environmental versus the spatial distances (Figure 3e,j). 
In comparison, the $\beta$-diversity of both the abundant and rare archaeal taxa was consistently associated with environmental distance in both soil layers (Figure 3o,t).
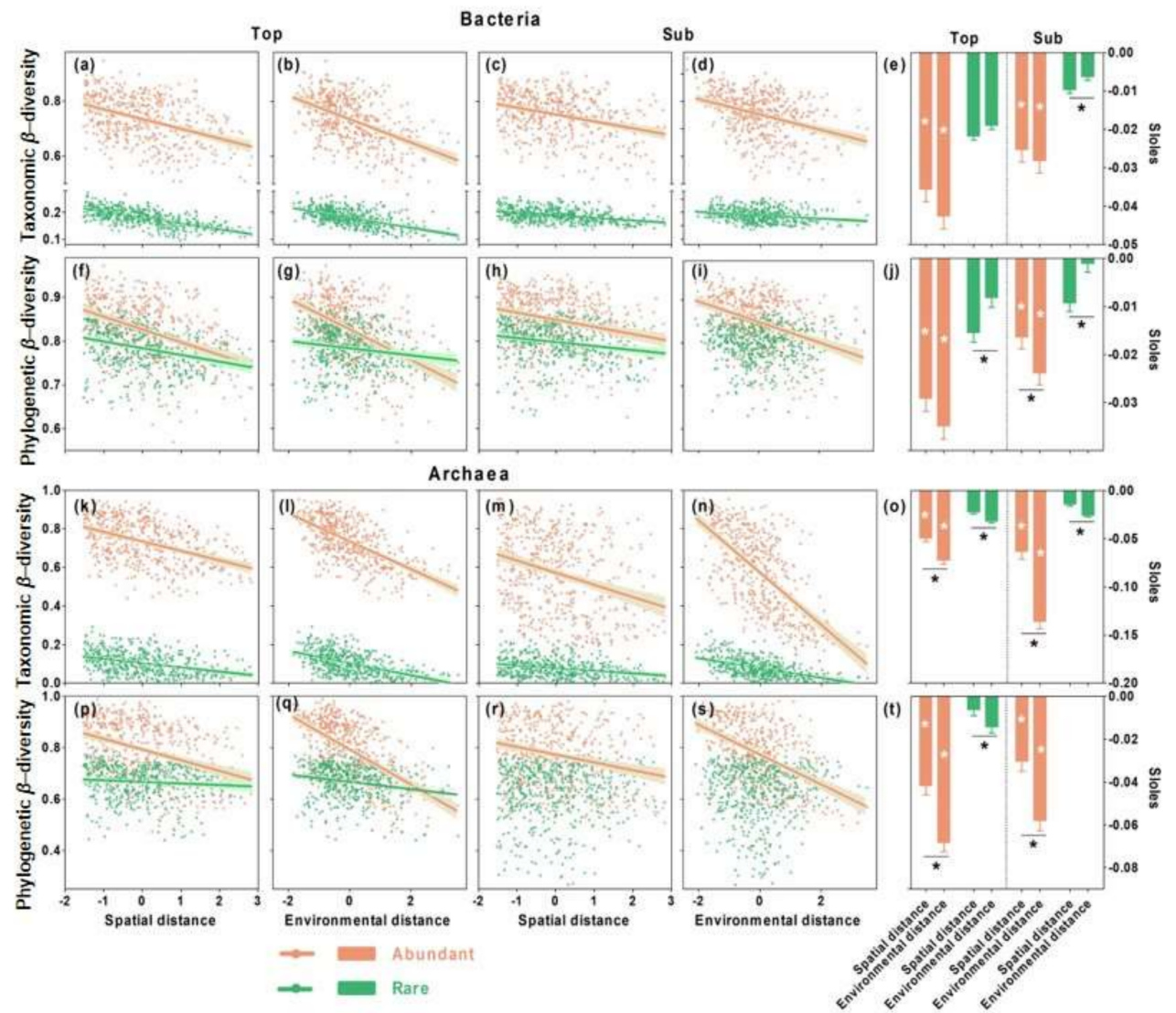

Figure 3. Taxonomic and phylogenetic $\beta$-diversity of abundant and rare bacteria $(\mathbf{a}-\mathbf{j})$ and archaea $(\mathbf{k}-\mathbf{t})$ taxa as functions of spatial and environmental distances and their corresponding slopes in topsoils and subsoils. Taxonomic and phylogenetic $\beta$-diversity was evaluated using Bray-Curtis and weighted UniFrac similarities, respectively. Green and salmon colours indicate abundant and rare microorganisms, respectively. Solid lines represent the significant linear regressions $(p<0.05)$ for the relationships between the $\beta$-diversity of the abundant (sample) and rare (green) taxa and distances evaluated by the Mantel test. The slopes between the $\beta$-diversity and spatial/environmental distances were compared between the abundant and rare microorganisms $\left({ }^{*}\right.$ on the bars) and between the spatial and environmental distances $\left({ }^{*}\right.$ below the bars) at $p<0.05$. Environmental distance was estimated as the Euclidean distance in the environmental space of the six environmental variables, including historical temperature anomaly, contemporary climate, aboveground vegetation, soil fertility, soil $\mathrm{pH}$, and soil mineral content (Table S2). Spatial and environmental distances were standardized to be comparable.

\subsection{Relative Importance of Spatial versus Environmental Distances on Microbial $\beta$-Diversity}

Together, the environmental and spatial distances explained the higher variations in the $\beta$-diversity (taxonomic and phylogenetic: 53.3 and $37.0 \%$, respectively) of the overall bacterial communities in the topsoils but the lower variations in the subsoils (only 27.5 and $15.3 \%$, respectively) (Figure $4 a$ ). The taxonomic $\beta$-diversity of the overall bacterial communities in both soil layers was mostly determined by deterministic processes, as indicated by the higher unique effect of environmental distance (topsoil, $25.4 \%$; subsoil, $47.4 \%$ ) than spatial distance (topsoil, 22.9\%; subsoil, 7.5\%; Figure 4b). Environmental distance showed a higher unique effect on the taxonomic $\beta$-diversity of the overall bacterial communities in the subsoils than in the topsoils when standardizing the unique effect (Figure $4 \mathrm{~b}$ ). However, the phylogenetic $\beta$-diversity of the overall bacterial communities in both soil layers was mostly determined by stochastic processes, as indicated by the 
higher unique effect of the spatial distance (topsoils, $42.1 \%$; subsoils, $24.7 \%$ ) than the environmental distance (topsoils, 9.9\%; subsoils, 24.3\%; Figure $4 \mathrm{~b}$ ).
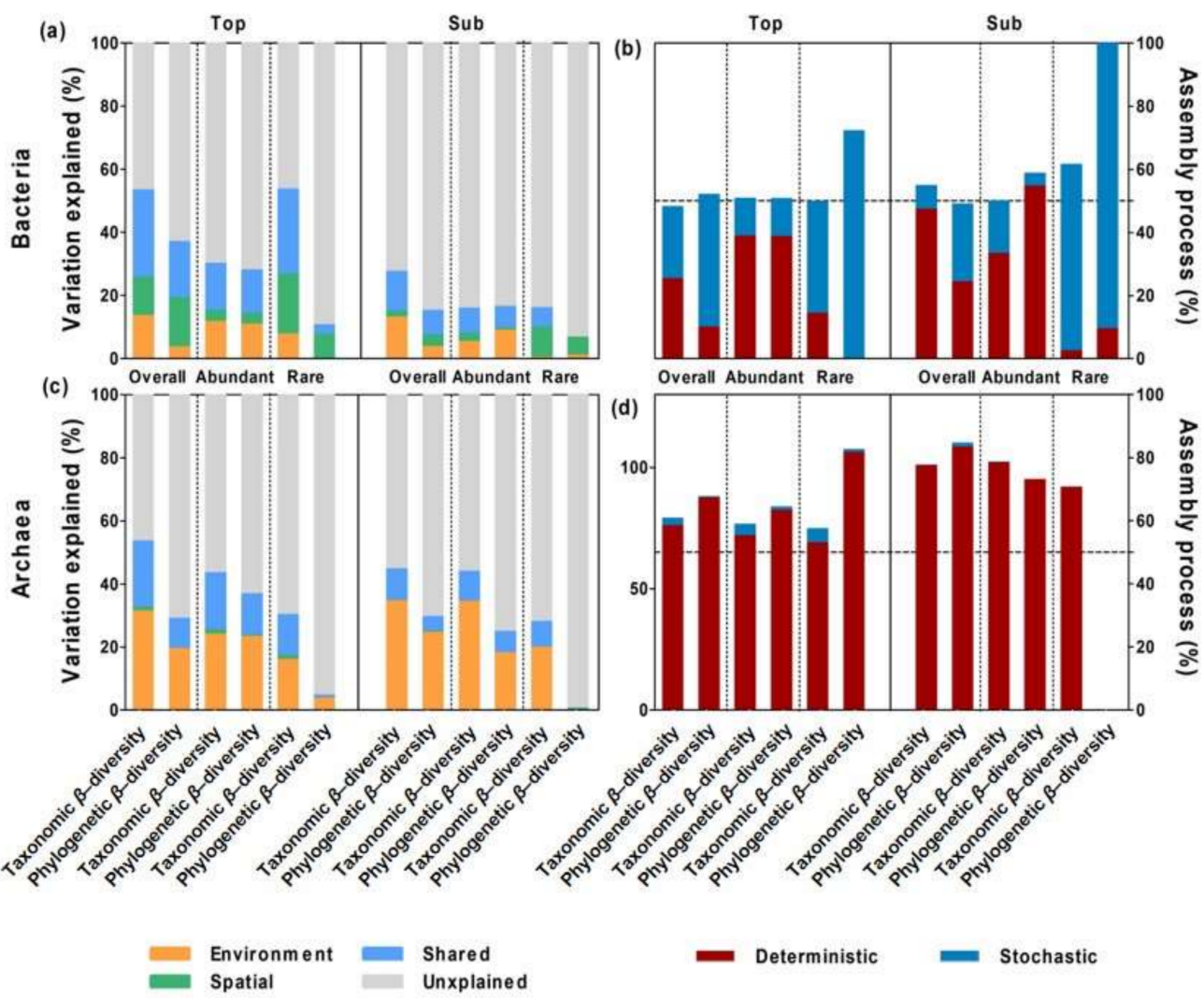

Figure 4. Relative contribution of environmental and spatial distances and of deterministic and stochastic processes to the $\beta$-diversity of bacterial $(\mathbf{a}, \mathbf{b})$ and archaeal $(\mathbf{c}, \mathbf{d})$ communities in topsoils and subsoils. Taxonomic and phylogenetic $\beta$-diversity was evaluated using Bray-Curtis and weighted UniFrac similarities, respectively. The effects of spatial and environmental distances on microbial $\beta$-diversity were evaluated using partial redundancy analysis, which partitioned the total variance into four parts: the independent spatial effect (green), independent environmental effect (salmon), shared (light blue) effects of the spatial and environmental distances, and residuals (grey). The deterministic processes (\%, red) were calculated as the percentage of the effects of environmental distance on the total effect of the environmental and spatial distances, while the stochastic processes $(\%$, dark blue) were calculated as the percentage of the effect of the spatial distance on the total effect of the environmental and spatial distances.

Similarly, the spatial and environmental distances together explained the higher variation in the $\beta$-diversity of the abundant (taxonomic and phylogenetic: 30.1 and $28.1 \%$, respectively) and rare (53.7 and $10.7 \%$, respectively) bacterial microorganisms in the topsoils but the lower variation in the $\beta$-diversity in the subsoils (15.9 and $16.5 \%$ for abundant; 16.1 and $5.8 \%$ for rare; Figure $4 \mathrm{a}$ ). The abundant bacterial microbes were mostly determined by deterministic processes in both soil layers, as indicated by the higher unique effect of the environmental distance (taxonomic and phylogenetic in topsoils: 38.9 and 38.7\%; 33.3 and $54.7 \%$ in subsoils) than the spatial (12.0 and $12.0 \%$ in topsoils; 16.7 and $4.1 \%$ in subsoils) distance on both $\beta$-diversities (Figure $4 \mathrm{~b}$ ). Rare bacterial microbes were mostly determined by stochastic processes in both soil layers, as indicated by the higher unique effect of the spatial distance (taxonomic and phylogenetic in topsoils: 35.4 and $72.2 \% ; 59.1$ and $90.6 \%$ in subsoils) than the environmental (14.4 and $0.01 \%$ in topsoils; 2.5 and $9.3 \%$ in subsoils) distance on both $\beta$-diversities (Figure $4 \mathrm{~b}$ ).

In comparison with the bacterial communities, together, the spatial and environmental distances explained the higher variation in the $\beta$-diversity of the overall (taxonomic 
and phylogenetic: 53.7 and $29.0 \%$ ), abundant ( 43.5 and $36.9 \%$ ), and rare ( 30.3 and $4.7 \%$ ) archaeal taxa in the topsoils, but relatively lower variation in the $\beta$-diversity in the subsoils (overall: 44.8 and 29.6\%; abundant: 44.0 and 24.9\%; rare: 28.1 and 0.5\%; Figure 4c). Overall, the abundant and rare archaeal taxa were consistently determined by deterministic processes, as indicated by the higher unique effect of the environmental distance than the spatial distance on the $\beta$-diversity (Figure $4 \mathrm{~d}$ ). Environmental distances showed a higher unique effect on the $\beta$-diversity of the archaeal communities in the subsoils than in the topsoils (Figure 4d).

\subsection{Ecological Mechanisms Underlying Microbial $\beta$-diversity}

To uncover the ecological mechanisms driving microbial $\beta$-diversity, the phylogenetic $\beta$-nearest taxon index ( $\beta$ NTI) and Bray-Curtis-based Raup-Crick $\left(\mathrm{RC}_{\text {Bray }}\right)$ metrics were calculated based on null model analysis (Figure 5). Across all sites, the bacterial communities in the topsoils were mostly determined by stochastic processes, especially 'undominated processes', such as weak selection, weak dispersal, diversification, and drift. However, the bacterial communities in the subsoils were equally determined by deterministic and stochastic processes (Figure 5a,c). Rare bacterial microbes (such as Thalassomonas, Sinorhizobium, Solirubrobacter, etc.) in both soil layers were mostly determined by stochastic processes (e.g., 'undominated processes'). By comparison, the archaeal communities and rare archaeal microbes in both soil layers were mostly determined by deterministic processes (e.g., homogenous selection; Figure 5b,d).
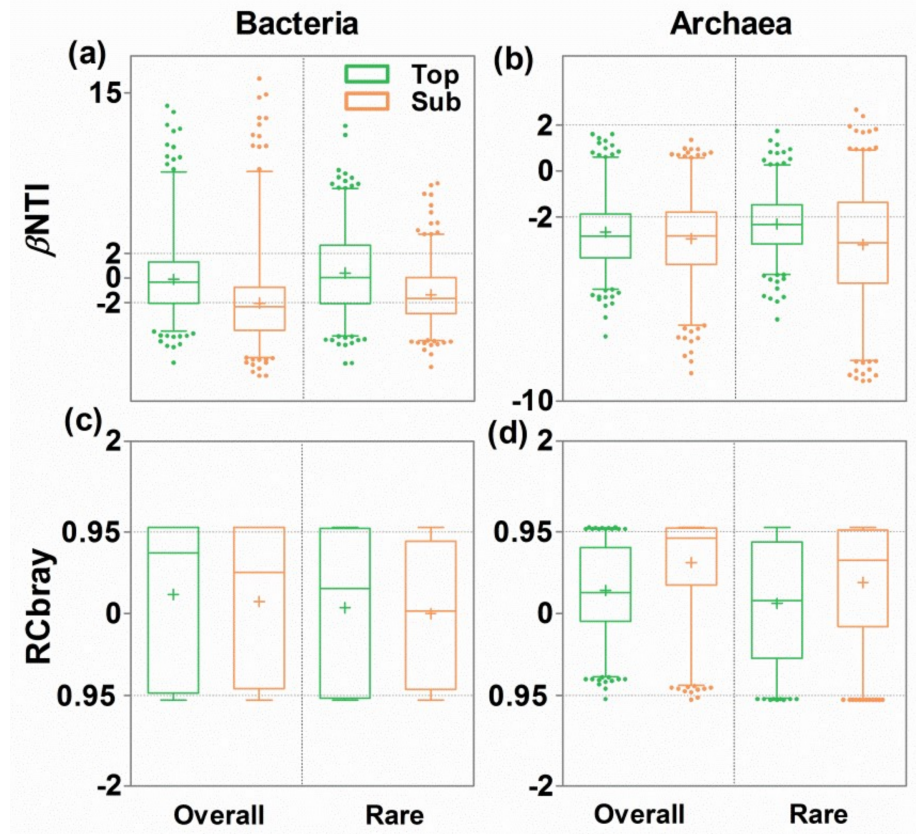

Figure 5. Variation in the $\beta$-nearest taxon index ( $\beta N T I,(a, b))$ and Bray-Curtis-based Raup-Crick matrix $\left(\mathrm{RC}_{\mathrm{Bray}},(\mathbf{c}, \mathbf{d})\right)$ based on null model expectations for bacterial $(\mathbf{a}, \mathbf{c})$ and archaeal $(\mathbf{b}, \mathbf{d})$ communities in topsoils and subsoils. " + " in each box indicates mean values. $\beta$ NTI $>2$ indicates variable selection, and $\beta \mathrm{NTI}<-2$ indicates homogenous selection. $|\beta \mathrm{NTI}|<2$ and $\mathrm{RC}_{\mathrm{Bray}}<-0.95$ indicate homogenous dispersal. $|\beta N T I|<2$ and $\mathrm{RC}_{\text {Bray }}>0.95$ indicate dispersal limitation. $|\beta \mathrm{NTI}|<2$ and $\left|\mathrm{RC}_{\text {Bray }}\right|<0.95$ mainly indicate 'undominated processes', such as weal selection, weak dispersal, diversification, and drift. Due to the cosmopolitan properties ( $100 \%$ across sites in our studies) of the abundant microbes, the $\beta$ NTI of the abundant microbes could not be calculated if the conspecific taxa in different communities were not excluded from MNTD calculations using the "comdistnt" functions in the "picante" packages of R. 


\subsection{Environmental Drivers of Microbial Community Composition}

Using random forest analyses (Figure 6), we found that among the spatial and the environmental distances of the six individual environmental variables, historical temperature anomaly was the main driver of both $\beta$-diversity measures (taxonomic and phylogenetic) of the overall bacterial microbes in topsoils, while the soil $\mathrm{pH}$ was the main driver in the subsoils. By comparison, aboveground vegetation was the main driver of both $\beta$-diversity measures of the abundant bacterial microbes in both soil layers (Figure 6). Historical temperature anomaly, contemporary climate, and spatial distance were the top three drivers of both $\beta$-diversity measures of the rare bacterial microbes in the topsoils, while the spatial distance and the historical temperature anomaly were the top two drivers in the subsoils (Figure 6).

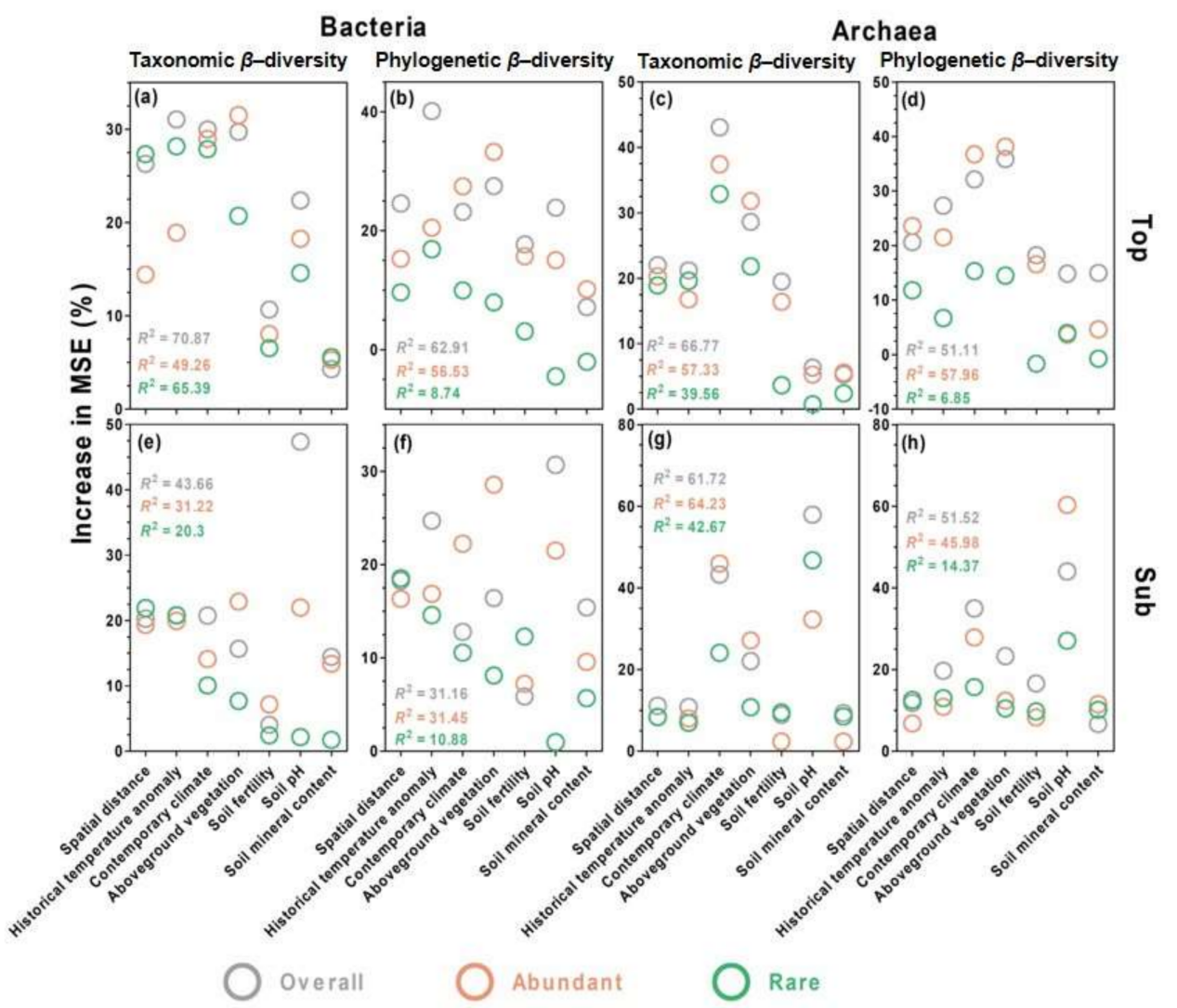

Figure 6. Relative contribution of the spatial distance and the distance of each individual environmental variable to soil bacterial $(\mathbf{a}, \mathbf{b}, \mathbf{e}, \mathbf{f})$ and archaeal $(\mathbf{c}, \mathbf{d}, \mathbf{g}, \mathbf{h}) \beta$-diversity in topsoils and subsoils. Taxonomic (a-d) and phylogenetic (e-h) $\beta$-diversity was evaluated using Bray-Curtis and weighted UniFrac similarities, respectively. The results were generated from random forest analyses.

In comparison with bacteria, contemporary climate, and aboveground vegetation were the top two drivers of both $\beta$-diversity measures of the overall, abundant, and rare archaeal taxa in the topsoils, while the soil $\mathrm{pH}$ and contemporary climate were the top two drivers of the $\beta$-diversity for the overall, abundant, and rare archaeal taxa in the subsoils (Figure 6).

\subsection{Niche Breadth}

The habitat niche breadths in the communities of the overall, abundant, and rare bacterial microbes were broader than those in the corresponding archaeal taxa in both soil layers (Figure 7). The communities of the abundant microbes of the two microbial domains had the widest niche breadths followed by those of the overall taxa, and the communities of rare microbes had the narrowest niche breadths $(p<0.05$; Figure 7$)$. More importantly, 
the habitat niche breadths were significantly broader $(p<0.05)$ in the subsoils than in the topsoils for all three bacterial communities but were significantly narrower in the subsoils than in the topsoils for all three archaeal communities (Figure 7).

Bacteria

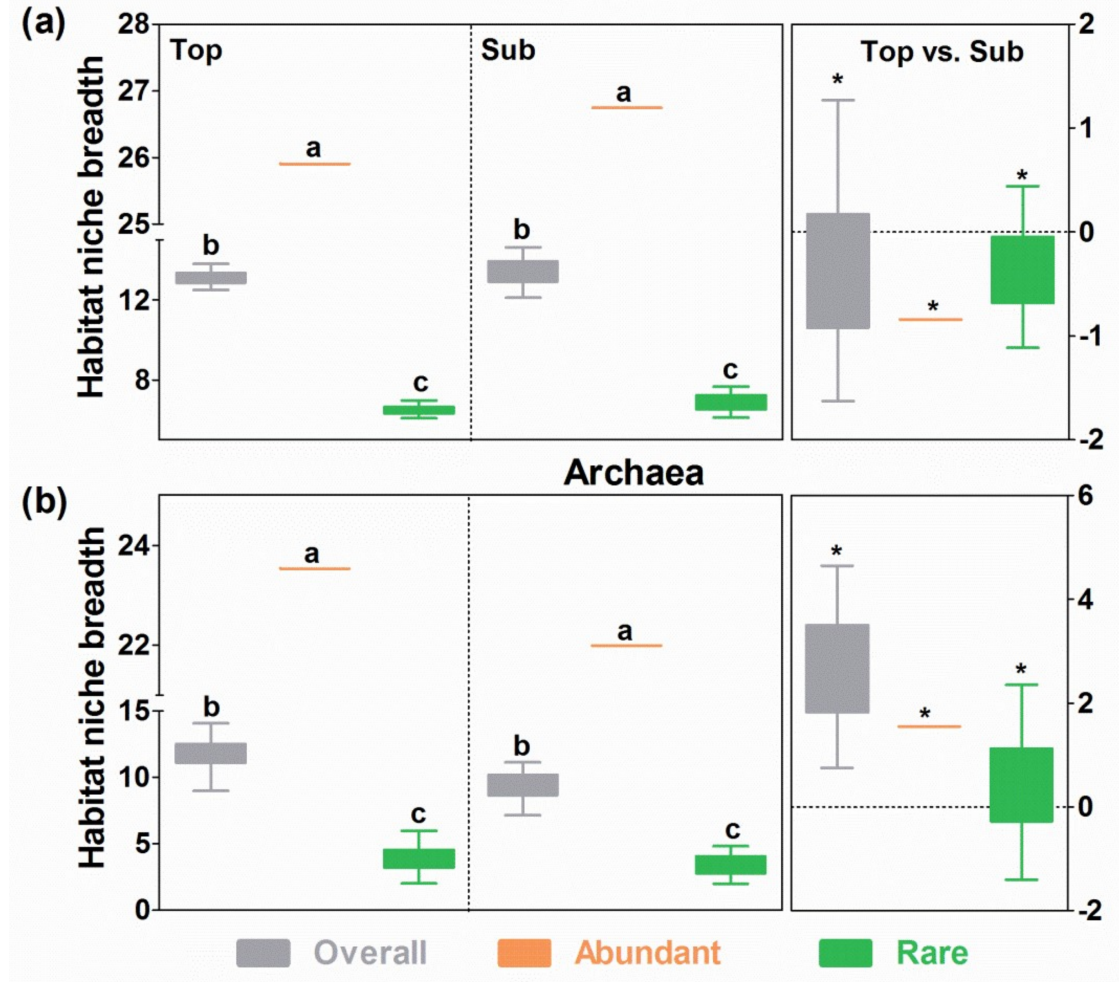

Figure 7. Habitat niche breadths of bacterial (a) and archaeal (b) communities in topsoils and subsoils. The right panels indicate the difference $\left({ }^{*}, p<0.05\right)$ in habitat niche breadths between topsoils and subsoils. The letters above bars indicate significance $(p<0.05)$ among overall, abundant, and rare microbial communities for bacteria and archaea, while the asterisks above bars on the right indicate significant differences $(p<0.05)$ between topsoils and subsoils for all microbial communities.

\section{Discussion}

\subsection{Consistent Community Assembly Processes across Soil Depths}

We observed a strong distance decay of community similarity along both the spatial and environmental distances in the bacterial and archaeal communities at both soil depths, which suggests that bacterial and archaeal $\beta$-diversity is jointly determined by stochastic and deterministic processes. This finding is consistent with the continuum hypothesis, suggesting that stochastic and deterministic processes interact to structure the assembly of microbial communities $[20,21]$. However, we found that the slopes of the distancedecay curves for bacterial taxonomic $\beta$-diversity and archaeal $\beta$-diversity (both taxonomic and phylogenetic) were higher across the environmental distance than across the spatial distance (Figure 2). Analyses of variation partitioning also showed that the environmental distance explained the higher variation in the bacterial taxonomic $\beta$-diversity and archaeal $\beta$-diversity (both taxonomic and phylogenetic) than the spatial distance (Figure 4 ). These results suggest that both bacterial taxonomic $\beta$-diversity and archaeal $\beta$-diversity in both soil layers tend to be determined by deterministic processes, supporting our first hypothesis. This is consistent with previous studies on agricultural ecosystems [22], grasslands [8,18], and aquatic ecosystems [5], all of which showed stronger effects of deterministic processes, especially in terms of homogenous selection to structure microbial $\beta$-diversity.

Deterministic processes tend to occur when long-distance dispersal is not limited [47]. Long-distance dispersal is possible in the grasslands of Inner Mongolia because there are winds and dust storms all year round that can transport near-surface soil hundreds of 
miles away. Previous studies found that wind speed or dust transport could influence the microbial distribution in water and in the near-surface atmosphere and make their geographic patterns more responsive to climatic and soil factors [48,49]. In addition to longdistance dispersal, strong environmental heterogeneity, such as the aridity gradient and vegetation types in harsh arid drylands may also lead to the strong effect of environmental factors on soil microbial composition changes, even across large spatial scales.

Though soil depth did not influence the identity of community assembly processes, it changed the relative strength of these processes. Specifically, in comparison with the topsoils, deterministic processes had a higher effect in the subsoils for both the bacterial and archaeal communities in terms of taxonomic $\beta$-diversity (Figure 4), suggesting that subsoil microbial communities are more strongly responsive to changing environment (such as soil pH, discussed in the last section) than those in topsoils (multiple environmental factors, historical climate, contemporary climate, and aboveground vegetation). The higher deterministic effects in subsoils than in topsoils are consistent with previous studies on prokaryote and fungal communities in drylands [11,12]. However, the low but still significant effect of deterministic processes in topsoil are not well consistent the abovementioned studies [11,12]; however, they are consistent with the bacterial communities in the topsoils of Tibetan grasslands [9]. This indicates that the topsoil microbial communities might be barely determined solely by the assembly mechanism due to complex geography and environmental conditions across landscapes, while the subsoil microbial communities might be easily deciphered based on deterministic mechanisms due to similar environmental conditions (lower substrate availability, better insulation from the atmosphere) across landscapes. The contrasting strength of assembly processes demonstrates the important role of soil-horizon partitioning in filtering specific microbial taxa in topsoils (such as Acidobacteria, Proteobacteria, Planctomycetes, Bacteroidetes, Firmicutes) and subsoils (such as Actinobacteria, Nitrospirae, Gemmatimonadetes) [9]. In the deterministic processes, heterogeneous and variable environmental conditions in topsoils, especially in near-surface soils support the co-occurrence of numerous microbial taxa, while the enclosed and stable environment in subsoils only supports the occurrence of oligotrophic taxa and high $\mathrm{pH}$-adapted taxa.

Most studies exploring community assembly mechanisms based on variation partitioning rarely compared the discrepancy between different $\beta$-diversity metrics (taxonomic versus phylogenetic) $[17,22]$. However, we found that the taxonomic and phylogenetic $\beta$-diversity of bacterial communities was determined by different processes based on variation partitioning. In contrast to taxonomic $\beta$-diversity, phylogenetic $\beta$-diversity was mainly driven by dispersal limitation in both soil layers, which does not support our first hypothesis. This finding is in contrast with a recent finding that bacterial communities are mainly determined by stochastic processes in topsoils and by deterministic processes in subsoils [12]. We suspect that phylogenetic $\beta$-diversity, including both weighted UniFrac and $\beta$ MNTD, considers phylogenetic relatedness between OTUs, while taxonomic $\beta$ diversity only considers OTU abundance [38]. In other words, phylogenetic $\beta$-diversity includes additional information on the evolution of bacterial OTUs compared to taxonomic $\beta$-diversity [50]. These results suggest that stochastic processes may play an important role in phylogenetic turnover among soil bacterial communities, which provides insights that are not accessible via the taxonomic turnover method [51]. More studies are needed to further decipher the assembly mechanisms of microbial communities using taxonomic versus phylogenetic $\beta$-diversity.

\subsection{Distinct Community Assembly Processes for Abundant and Rare Bacterial Microbes}

Both abundant and rare bacterial microbes showed a decrease in community similarity across spatial and environmental distances, showing distance-decay patterns. However, abundant bacterial microbes had a higher taxonomic and phylogenetic turnover (higher slopes of distance-decay curves) than rare bacterial microbes in both soil layers (Figure 3). This is in contrast to our expectation but is consistent with previous find- 
ings in forest ecosystems [52] and oil-contaminated soil [53]. One possible reason for the different species turnover (slopes in DDRs) between abundant and rare bacterial microbes may be because abundant microbes are more highly aggregated than rare microbes, which influences the distance decay in community similarity along both the spatial and environmental distances [52].

Despite the similarities in the $\beta$-diversity of abundant and rare bacterial microbes, we found that abundant bacterial microbes were more strongly determined by deterministic processes, while rare bacterial microbes were more strongly determined by stochastic processes, which supports our second hypothesis. In general, abundant microbes (such as Rubrobacter, Bradyrhizobium, Mycobacterium, and Steroidobacter) were all cosmopolitan (100\% across sites in our studies), had high local abundance, and occupied a wider niche (Figures 1 and 6). Thus, they could competitively use different kinds of resources and could adapt to different environments (such as the response to aboveground vegetation, discussed in the last section) more effectively [53]. Therefore, abundant microbes may be less limited by dispersal than rare microbes, even at large geographic scales and thus can sufficiently be delivered to suitable habitats with suitable environmental conditions [47]. In contrast, rare microbes (such as Nocardioides, Actinomadura, Inquilinus, and Paenibacillus) normally have low local abundance and weak competitive ability. Therefore, the $\beta$-diversity of rare bacterial microbes is more strongly driven by stochastic processes, including weak environmental filtering and weak dispersal.

The finding on the distinct community assembly mechanisms between abundant and rare bacterial microbes provides insights into the inconsistent argument on the assembly mechanisms between abundant and rare microbial taxa in numerous ecosystems (such as grasslands, agriculture, and water ecosystems) [25-27]. Our study demonstrated that abundant microbes tended to be determined by environmental filtering, perhaps due to their good adaptation to the surrounding environment and strong dispersal ability, while rare microbes tended to be determined by stochasticity due to the effects of their weak dispersal ability and historical contingency on their distributions [3].

\subsection{Distinct Environmental Drivers of $\beta$-Diversity across Soil Depths and Microbial Groups}

Although deterministic processes predominated the bacterial and archaeal $\beta$-diversity in both soil layers, the effect of the environmental factors representing the effects of deterministic processes varied across soil depths, confirming our third hypothesis. In general, the bacterial and archaeal $\beta$-diversity in the topsoils tended to be determined by contemporary and past climate or aboveground vegetation, while the $\beta$-diversity in the subsoils tended to be determined by edaphic factors, e.g., soil $\mathrm{pH}$. These results suggest that different environmental conditions across soil depths may have filtered different microbial community compositions.

In topsoils, bacterial $\beta$-diversity was dominated by historical temperature anomaly rather than by contemporary climates. Similarly, recent studies have found that the paleoclimate since the Last Glacial Maximum (LGM) explains more variation in the composition of bacterial communities than the current climate does because the paleoclimate may influence the compositions of soil bacterial communities by its effect on present-day microbial enzyme sensitivity or soil properties [54,55]. In contrast, the archaeal $\beta$-diversity in the topsoils was dominated by analyzing the contemporary climate and aboveground vegetation rather than by means of the historical temperature anomaly, which suggests that archaeal communities are more rapidly responsive to recent climate dynamics and plant carbon input compared to bacteria [56]. For example, the archaeal Parvarchaeota, an acidophilic group [57], can assimilate multiple carbon resources (e.g., starch, cellulose, disaccharides) and is positively responsive to aboveground plant biomass [28].

In contrast to topsoils, microbial taxa in subsoils, such as Actinobacteria, are more adaptive to oligotrophic environments and are more related to soil geochemistry [10]; hence, the microbial $\beta$-diversity in subsoils tends to be determined by edaphic factors rather than by climate and aboveground vegetation. Indeed, our results demonstrated 
that soil $\mathrm{pH}$ was a stronger environmental driver in structuring microbial communities in subsoils than in topsoils in Inner Mongolia grasslands, which is in contrast to previous studies on other ecosystems showing a stronger $\mathrm{pH}$ effect on the soil microbial communities in topsoils than in subsoils [17].

\section{Conclusions}

In the present study, we found that in general, deterministic processes had stronger effects on soil bacterial and archaeal $\beta$-diversity in both top- and subsoils than stochastic processes. However, we found that the relative effects of deterministic and stochastic processes on $\beta$-diversity and the major environmental drivers representing deterministic process varied between taxonomic and phylogenetic $\beta$-diversity, between the different soil layers, and between the abundant and rare microbes. The taxonomic $\beta$-diversity of the overall bacterial communities and the $\beta$-diversity of the abundant bacteria was more strongly determined by deterministic processes, while the phylogenetic $\beta$-diversity of the overall bacterial communities and the $\beta$-diversity of rare bacteria was more strongly determined by stochastic processes. In contrast, archaeal $\beta$-diversity was consistently more strongly determined by deterministic processes. The microbial $\beta$-diversity in the topsoils and for the abundant microbes was more strongly determined by contemporary and historical climate and aboveground vegetation, while the microbial $\beta$-diversity in the subsoils was more strongly determined by soil geochemistry. This reminds us to comprehensively consider multiple aspects of microbial communities when evaluating their assembly processes, which would improve our understanding of the assembly of soil microbial communities under a changing environment.

Supplementary Materials: The following are available online at https:/ /www.mdpi.com/article/ 10.3390/microorganisms9091929/s1, Table S1: Comparison of dissimilarity of soil microbial communities between top- and subsoils in temperate grasslands with different statistical approaches. Table S2: First principal component (PC 1) extracted from the principal component analysis (PCA) for the five environmental groups and results of Kaise-Meyer-Olkin (KMO) test and Bartlett test of sphericity (BS) for the variables used for the principal component analysis (PCA) in the paper. Figure S1: Sampling sites along an aridity gradient in arid and semi-arid grasslands. In total, 32 sites were sampled across desert (yellow dot), typical (blue dot), and meadow (purple dot) steppes from the southwest towards the northeast. MAP denotes mean annual precipitation in $\mathrm{mm}$, which was obtained from the WorldClim website (http:/ / worldclim.org/version2 accessed on 10 May 2017) [30]. The climatic and soil variables are available in the Supplementary Data.

Author Contributions: Conceptualization and funding acquisition, Z.W., X.F. and N.L.; methodology and experiments, N.L.; software, Y.D.; bioinformatics analysis, N.L., A.L. and J.M.; resources, W.M. and H.H.; data curation, N.L. and Z.W.; writing—original draft preparation, N.L.; writing—review and editing, Z.W., X.F. and Q.W.; visualization, N.L.; supervision, Z.W. and X.F.; project administration, Z.W., X.F. and N.L. All authors have read and agreed to the published version of the manuscript.

Funding: This research was funded by the National Natural Science Foundation of China, grant numbers 32125026 and 31988102, the Chinese Academy of Sciences K. C. Wong Education Foundation (GJTD-2019-10), and the Youth Fund of Ministry of Education Laboratory for Earth Surface Processes of Peking University (grant number LESP201702).

Institutional Review Board Statement: Not applicable.

Informed Consent Statement: Not applicable.

Data Availability Statement: The names of the accession number(s) can be found in the paper.

Acknowledgments: We thank K. Feng for the help with the bioinformatics pipelines.

Conflicts of Interest: The authors declare no conflict of interest.

\section{References}

1. Zhou, J.Z.; Ning, D.L. Stochastic community assembly: Does it matter in microbial ecology? Microbiol. Mol. Biol. Rev. 2017, 81, e00002-17. [CrossRef] [PubMed] 
2. Hanson, C.A.; Fuhrman, J.A.; Horner-Devine, M.C.; Martiny, J.B. Beyond biogeographic patterns: Processes shaping the microbial landscape. Nat. Rev. Microbiol. 2012, 10, 497-506. [CrossRef]

3. Wang, Z.H.; Fang, J.Y.; Tang, Z.Y.; Shi, L. Geographical patterns in the beta diversity of China's woody plants: The influence of space, environment and range size. Ecography 2012, 35, 1092-1102. [CrossRef]

4. Ozkan, K.; Svenning, J.C.; Jeppesen, E. Environmental species sorting dominates forest-bird community assembly across scales. J. Anim. Ecol. 2013, 82, 266-274. [CrossRef]

5. Wang, J.J.; Shen, J.; Wu, Y.C.; Tu, C.; Soininen, J.; Stegen, J.C.; He, J.Z.; Liu, X.Q.; Zhang, L.; Zhang, E.L. Phylogenetic beta diversity in bacterial assemblages across ecosystems: Deterministic versus stochastic processes. ISME J. 2013, 7, 1310-1321. [CrossRef]

6. Stegen, J.C.; Lin, X.; Fredrickson, J.K.; Chen, X.; Kennedy, D.W.; Murray, C.J.; Rockhold, M.L.; Konopka, A. Quantifying community assembly processes and identifying features that impose them. ISME J. 2013, 7, 2069-2079. [CrossRef]

7. Huang, M.K.; Chai, L.W.; Jiang, D.L.; Zhang, M.J.; Zhao, Y.R.; Huang, Y. Increasing aridity affects soil archaeal communities by mediating soil niches in semi-arid regions. Sci. Total Environ. 2019, 647, 699-707. [CrossRef] [PubMed]

8. Wang, X.B.; Lu, X.T.; Yao, J.; Wang, Z.W.; Deng, Y.; Cheng, W.X.; Zhou, J.Z.; Han, X.G. Habitat-specific patterns and drivers of bacterial beta-diversity in China's drylands. ISME J. 2017, 11, 1345-1358. [CrossRef] [PubMed]

9. Chu, H.Y.; Sun, H.B.; Tripathi, B.M.; Adams, J.M.; Huang, R.; Zhang, Y.J.; Shi, Y. Bacterial community dissimilarity between the surface and subsurface soils equals horizontal differences over several kilometers in the western Tibetan Plateau. Environ. Microbiol. 2016, 18, 1523-1533. [CrossRef] [PubMed]

10. Rumpel, C.; Chabbi, A.; Marschner, B. Carbon storage and sequestration in subsoil horizons: Knowledge, gaps and potentials. p. 445-464. In Recarbonization of the Biosphere: Ecosystems and the Global Carbon Cycle; Lal, R., Lorenz, K., Hüttl, R., Uwe Schneider, B., von Braun, J., Eds.; Springer: Berlin/Heidelberg, Germany, 2012.

11. Yang, T.; Adams, J.M.; Shi, Y.; He, J.-S.; Jing, X.; Chen, L.T.; Tedersoo, L.; Chu, H.Y. Soil fungal diversity in natural grasslands of the Tibetan Plateau: Associations with plant diversity and productivity. New Phytol. 2017, 215, 756-765. [CrossRef]

12. Du, X.F.; Deng, Y.; Li, S.Z.; Escalas, A.; Feng, K.; He, Q.; Wang, Z.J.; Wu, Y.N.; Wang, D.; Peng, X.; et al. Steeper spatial scaling patterns of subsoil microbiota are shaped by deterministic assembly process. Mol. Ecol. 2020, 30, 1072-1085. [CrossRef]

13. de Wit, R.; Bouvier, T. 'Everything is everywhere, but the environment selects'; what did baas becking and beijerinck really say? Environ. Microbiol. 2006, 8, 755-758. [CrossRef]

14. Chase, J.M.; Myers, J.A. Disentangling the importance of ecological niches from stochastic processes across scales. Philos. Trans. $R$. Soc. Lond. B Biol. Sci. 2011, 366, 2351-2363. [CrossRef] [PubMed]

15. Green, J.L.; Holmes, A.J.; Westoby, M.; Oliver, I.; Briscoe, D.; Dangerfield, M.; Gillings, M.; Beattie, A.J. Spatial scaling of microbial eukaryote diversity. Nature 2004, 432, 747-750. [CrossRef]

16. Chase, J.M.; Kraft, N.J.B.; Smith, K.G.; Vellend, M.; Inouye, B.D. Using null models to disentangle variation in community dissimilarity from variation in $\alpha$-diversity. Ecosphere 2011, 2, art24. [CrossRef]

17. Tripathi, B.M.; Stegen, J.C.; Kim, M.; Dong, K.; Adams, J.M.; Lee, Y.K. Soil pH mediates the balance between stochastic and deterministic assembly of bacteria. ISME J. 2018, 12, 1072-1083. [CrossRef]

18. Dumbrell, A.J.; Nelson, M.; Helgason, T.; Dytham, C.; Fitter, A.H. Relative roles of niche and neutral processes in structuring a soil microbial community. ISME J. 2010, 4, 337-345. [CrossRef] [PubMed]

19. Dini-Andreote, F.; Stegen, J.C.; van Elsas, J.D.; Salles, J.F. Disentangling mechanisms that mediate the balance between stochastic and deterministic processes in microbial succession. Proc. Natl. Acad. Sci. USA 2015, 112, E1326-E1332. [CrossRef]

20. Caruso, T.; Chan, Y.K.; Lacap, D.C.; Lau, M.C.; McKay, C.P.; Pointing, S.B. Stochastic and deterministic processes interact in the assembly of desert microbial communities on a global scale. ISME J. 2011, 5, 1406-1413. [CrossRef] [PubMed]

21. Powell, J.R.; Karunaratne, S.; Campbell, C.D.; Yao, H.Y.; Robinson, L.; Singh, B.K. Deterministic processes vary during community assembly for ecologically dissimilar taxa. Nat. Commun. 2015, 6, 8444. [CrossRef] [PubMed]

22. Shi, Y.; Li, Y.T.; Xiang, X.J.; Sun, R.B.; Yang, T.; He, D.; Zhang, K.P.; Ni, Y.Y.; Zhu, Y.G.; Adams, J.M.; et al. Spatial scale affects the relative role of stochasticity versus determinism in soil bacterial communities in wheat fields across the north China plain. Microbiome 2018, 6, 27. [CrossRef]

23. Siqueira, T.; Bini, L.M.; Roque, F.O.; Marques Couceiro, S.R.; Trivinho-Strixino, S.; Cottenie, K. Common and rare species respond to similar niche processes in macroinvertebrate metacommunities. Ecography 2012, 35, 183-192. [CrossRef]

24. Cornwell, W.K.; Ackerly, D. A link between plant traits and abundance: Evidence from coastal California woody plants. J. Ecol. 2010, 98, 814-821. [CrossRef]

25. Jiao, S.; Lu, Y.H. Soil $\mathrm{pH}$ and temperature regulate assembly processes of abundant and rare bacterial communities in agricultural ecosystems. Environ. Microbiol. 2020, 22, 1052-1065. [CrossRef] [PubMed]

26. Ji, M.K.; Kong, W.D.; Stegen, J.; Yue, L.Y.; Wang, F.; Dong, X.B.; Cowan, D.A.; Ferrari, B.C. Distinct assembly mechanisms underlie similar biogeographical patterns of rare and abundant bacteria in Tibetan Plateau grassland soils. Environ. Microbiol. 2020, 22, 2261-2272. [CrossRef] [PubMed]

27. Liu, L.M.; Yang, J.; Yu, Z.; Wilkinson, D.M. The biogeography of abundant and rare bacterioplankton in the lakes and reservoirs of China. ISME J. 2015, 9, 2068-2077. [CrossRef] [PubMed]

28. Liu, N.N.; Hu, H.F.; Ma, W.H.; Deng, Y.; Liu, Y.Q.; Hao, B.H.; Zhang, X.Y.; Dimitrov, D.; Feng, X.J.; Wang, Z.H. Contrasting biogeographic patterns of bacterial and archaeal diversity in the top- and subsoils of temperate grasslands. $m S y s t e m s \mathbf{2 0 1 9}, 4$, e00566-19. [CrossRef] 
29. Wang, T.; Xu, S.; Zhao, M.Y.; Li, H.; Kou, D.; Fang, J.Y.; Hu, H.F. Allocation of mass and stability of soil aggregate in different types of Nei Mongol grasslands. Chin. J. Plant Ecol. 2017, 41, 1168-1176.

30. Bai, Y.F.; Wu, J.G.; Xing, Q.; Pan, Q.M.; Huang, J.H.; Yang, D.L.; Han, X.G. Primary production and rain use efficiency across a precipitation gradient on the Mongolia Plateau. Ecology 2008, 89, 2140-2153. [CrossRef]

31. Watanabe, S.; Hajima, T.; Sudo, K.; Nagashima, T.; Takemura, T.; Okajima, H.; Nozawa, T.; Kawase, H.; Abe, M.; Yokohata, T.; et al MIROC-ESM: Model description and basic results of CMIP5-20c3m experiments. Geosci. Model Dev. Discuss. 2011, 4, 1063-1128.

32. Hijmans, R.J.; Cameron, S.E.; Parra, J.L.; Jones, P.G.; Jarvis, A. Very high resolution interpolated climate surfaces for global land areas. Int. J. Clim. 2005, 25, 1965-1978. [CrossRef]

33. Leff, J.W.; Jones, S.E.; Prober, S.M.; Barberan, A.; Borer, E.T.; Firn, J.L.; Harpole, W.S.; Hobbie, S.E.; Hofmockel, K.S.; Knops, J.M.; et al. Consistent responses of soil microbial communities to elevated nutrient inputs in grasslands across the globe. Proc. Natl. Acad. Sci. USA 2015, 112, 10967-10972. [CrossRef]

34. Zhang, J.W.; Tang, H.Y.; Zhu, J.G.; Lin, X.G.; Feng, Y.Z. Divergent responses of methanogenic archaeal communities in two rice cultivars to elevated ground-level $\mathrm{O}_{3}$. Environ. Pollut. 2016, 213, 127-134. [CrossRef] [PubMed]

35. Edgar, R.C. UPARSE: Highly accurate OTU sequences from microbial amplicon reads. Nat. Methods 2013, 10, 996-998. [CrossRef]

36. Feng, K.; Zhang, Z.J.; Cai, W.W.; Liu, W.Z.; Xu, M.Y.; Yin, H.Q.; Wang, A.J.; He, Z.L.; Deng, Y. Biodiversity and species competition regulate the resilience of microbial biofilm community. Mol. Ecol. 2017, 26, 6170-6182. [CrossRef]

37. Dai, T.J.; Zhang, Y.; Tang, Y.S.; Bai, Y.H.; Tao, Y.L.; Huang, B.; Wen, D.H. Identifying the key taxonomic categories that characterize microbial community diversity using full-scale classification: A case study of microbial communities in the sediments of Hangzhou Bay. FEMS Microbiol. Ecol. 2016, 92, fiw150. [CrossRef] [PubMed]

38. Lozupone, C.; Knight, R. UniFrac: A new phylogenetic method for comparing microbial communities. Appl. Environ. Microbiol. 2005, 71, 8228-8235. [CrossRef] [PubMed]

39. Anderson, M.J.; Ellingsen, K.E.; McArdle, B.H. Multivariate dispersion as a measure of beta diversity. Ecol. Lett. 2006, 9, 683-693. [CrossRef] [PubMed]

40. Jackson, D.A.; Somers, K.M. Are probability estimates from the permutation model of mantel's test stable? Can. J. Zool. 1989, 67, 766-769. [CrossRef]

41. Lenth, R.V. Least-squares means: The r package lsmeans. J. Stat. Softw. 2016, 69, 1-33. [CrossRef]

42. Borcard, D.; Legendre, P.; Drapeau, P. Partialling out the spatial component of ecological variation. Ecology 1992, 73, 1045-1055. [CrossRef]

43. Breiman, L. Random forests. Mach. Learn. 2001, 45, 5-32. [CrossRef]

44. Liaw, A.; Wiener, M. Classification and regression by randomForest. R. News 2002, 2, 18-22.

45. Wu, W.X.; Lu, H.P.; Sastri, A.; Yeh, Y.C.; Gong, G.C.; Chou, W.C.; Hsieh, C.H. Contrasting the relative importance of species sorting and dispersal limitation in shaping marine bacterial versus protist communities. ISME J. 2018, 12, 485-494. [CrossRef]

46. Zhang, J.L. Spaa: Species Association Analysis; R Package Version 0.2.1.; The R Project for Statistical Computing: Vienna, Austria, 2013.

47. Cottenie, K. Integrating environmental and spatial processes in ecological community dynamics. Ecol. Lett. 2005, 8, 1175-1182. [CrossRef]

48. Smith, P.; Carroll, C.; Wilkins, B.; Johnson, P.; Gabhainn, S.N.; Smith, L.P. The effect of wind speed and direction on the distribution of sewage-associated bacteria. Lett. Appl. Microbiol. 1999, 28, 184-188. [CrossRef]

49. Barberan, A.; Ladau, J.; Leff, J.W.; Pollard, K.S.; Menninger, H.L.; Dunn, R.R.; Fierer, N. Continental-scale distributions of dust-associated bacteria and fungi. Proc. Natl. Acad. Sci. USA 2015, 112, 5756-5761. [CrossRef] [PubMed]

50. Li, M.J.; Liu, J.F.; Tonkin, J.D.; Shen, J.; Xiao, N.W.; Wang, J.J. The effects of abiotic and biotic factors on taxonomic and phylogenetic diversity of stream epilithic bacteria around Qiandao Lake. Aquat. Sci. 2020, 82, 71. [CrossRef]

51. Stegen, J.C.; Lin, X.; Konopka, A.E.; Fredrickson, J.K. Stochastic and deterministic assembly processes in subsurface microbial communities. ISME J. 2012, 6, 1653-1664. [CrossRef] [PubMed]

52. Morlon, H.; Chuyong, G.; Condit, R.; Hubbell, S.; Kenfack, D.; Thomas, D.; Valencia, R.; Green, J.L. A general framework for the distance-decay of similarity in ecological communities. Ecol. Lett. 2008, 11, 904-917. [CrossRef]

53. Jiao, S.; Chen, W.M.; Wei, G.H. Biogeography and ecological diversity patterns of rare and abundant bacteria in oil-contaminated soils. Mol. Ecol. 2017, 26, 5305-5317. [CrossRef] [PubMed]

54. Delgado-Baquerizo, M.; Bissett, A.; Eldridge, D.J.; Maestre, F.T.; He, J.Z.; Wang, J.T.; Hamonts, K.; Liu, Y.R.; Singh, B.K.; Fierer, N. Palaeoclimate explains a unique proportion of the global variation in soil bacterial communities. Nat. Ecol. Evol. 2017, 1, 1339-1347. [CrossRef] [PubMed]

55. Averill, C.; Waring, B.G.; Hawkes, C.V. Historical precipitation predictably alters the shape and magnitude of microbial functional response to soil moisture. Glob. Chang. Biol. 2016, 22, 1957-1964. [CrossRef] [PubMed]

56. Bates, S.T.; Berg-Lyons, D.; Caporaso, J.G.; Walters, W.A.; Knight, R.; Fierer, N. Examining the global distribution of dominant archaeal populations in soil. ISME J. 2011, 5, 908-917. [CrossRef] [PubMed]

57. Luo, G.W.; Rensing, C.; Chen, H.; Liu, M.Q.; Wang, M.; Guo, S.W.; Ling, N.; Shen, Q.R. Deciphering the associations between soil microbial diversity and ecosystem multifunctionality driven by long-term fertilization management. Funct. Ecol. 2018, 32, 1103-1116. [CrossRef] 